\title{
Unique perception of clinical trials by Korean cancer patients
}

\author{
Su Jin Lee ${ }^{1 \dagger}$, Lee Chun Park ${ }^{2 \dagger}$, Jeeyun Lee ${ }^{1 *}$, Seonwoo Kim³ ${ }^{3}$ Moon Ki Choi ${ }^{1}$, Jung Yong Hong ${ }^{1}$, Sylvia Park1, \\ Chi Hoon Maeng ${ }^{1}$, Wonjin Chang ${ }^{1}$, Young Saing Kim', Se Hoon Park', Joon Oh Park', Ho Yeong Lim', \\ Won Ki Kang ${ }^{1}$ and Young Suk Park ${ }^{1 *}$
}

\begin{abstract}
Background: In the past few years, the number of clinical trials has increased rapidly in East Asia, especially for gastric and hepatobiliary cancer that are prevalent in Asian populations. However, the actual degree of understanding or perceptions of clinical trials by cancer patients in East Asian countries have seldom been studied.

Methods: Between July $1^{\text {st }}$ and November $30^{\text {th }}$ of 2011, we conducted a prospective study to survey cancer patients regarding their awareness of, and willingness to participate in, a clinical trial. Patients with gastrointestinal/ hepatobiliary cancer who visited the Hematology-Oncology outpatient clinic at Samsung Medical Center (SMC) were enrolled. A total of 21 questions were asked including four questions which used the Visual analogue scale (VAS) score.

Results: In this survey study, 1,000 patients were asked to participate and 675 patients consented to participate (67.5\%). The awareness of clinical trials was substantially higher in patients who had a higher level of education $(p<0.001)$, were married $(p=0.004)$, and had a higher economic status $(p=0.001)$. However, the willingness to participate in a clinical trial was not affected by the level of education or economic status of patients. The most influential factors for patient willingness to participate were a physician recommendation $(n=181,26.8 \%)$, limited treatment options ( $n=178,26.4 \%)$, and expectations of effectiveness of new anti-cancer drugs $(n=142,21.0 \%)$. Patients with previous experience in clinical trials had a greater willingness to participate in clinical trials compared to patients without previous experience $(p<0.001)$.
\end{abstract}

Conclusions: This large patient cohort survey study showed that Korean cancer patients are more aware of clinical trials, but awareness did not translate into willingness to participate.

Keywords: Cancer clinical trial, Survey, Awareness and willingness to participate

\section{Background}

Oncology is one of the most rapidly developing fields in medicine and a greater understanding of tumours at the molecular level has resulted in the development of many novel therapeutic agents. Cancer clinical trials are needed to evaluate the efficacy and toxicity of these newly-developed agents and have become an essential component of oncology [1,2]. Besides the design of the trial and the efficacy of the drug, the key success factor

\footnotetext{
* Correspondence: jyunlee@skku.edu; psy27hmo@samsung.com

${ }^{\dagger}$ Equal contributors

'Division of Hematology/Oncology, Department of Medicine, Samsung Medical Center, Sungkyunkwan University School of Medicine, 50 Irwondong Gangnam-gu, Seoul 135-710, Korea

Full list of author information is available at the end of the article
}

to conducting an effective clinical trial is an understanding and awareness of clinical trials by cancer patients. Patient attitude towards a clinical trial could greatly influence patient recruitment and retention. Although general attitudes towards clinical trials are positive in Western Countries, the number of patients actually enrolled in clinical trials tends to be low [3-7]. The known barriers to successful clinical trials include changes in hospital administrative systems, fewer eligible patients than anticipated (inaccurate feasibility), problems inherent in certain types of trials or methodology (e.g. placebo control), no treatment arms (supportive care only), and difficulties in describing randomization [8-10]. One of the major patient-related factors affecting the success of 
clinical trials is a lack of understanding of or low awareness by the patients themselves, which may impede patient accrual. Hence, it is necessary to understand the perception of clinical trials by cancer patients.

Previous studies have used questionnaires to examine patient expectation and understanding of clinical trials, to elucidate existing barriers and to improve the processes of clinical trials [11-14]. The National Cancer Institute (NCI) estimated that less than 5\% of newly diagnosed adult cancer patients are enrolled in clinical trials in the United States [1]. In Asia, even though the number of clinical trials has increased rapidly in the past decade, especially for cancer types prevalent in the Asian population, the awareness, understanding and/or willingness to participate has scarcely been reported. In fact, Korea leads Asia in patient recruitment for cancer trials and is $10^{\text {th }}$ in the world [15]. Owing to a relatively short history of cancer clinical trials and cultural differences in the doctor-patient relationship, Western data on patient attitude may not be directly applicable to such Eastern populations. In addition, cancer type could also affect the perception of and participation in a clinical trial, but few studies have addressed these questions [16].

The aim of this study was therefore to survey and analyze the degree of understanding and perceptions of clinical trials in Korea.

\section{Methods}

\section{Data collection}

From July $1^{\text {st }}$ to November $30^{\text {th }}$ of 2011 , we surveyed cancer patients who were diagnosed with gastrointestinal cancer (including gastric, colorectal, esophageal, small intestinal, hepatobiliary, and pancreatic cancer) at Samsung Medical Center in Korea and who visited the outpatient clinic at the Division of Hematology-Oncology. The eligibility criteria were: 1) aged $>19$ years; 2) histologically confirmed gastrointestinal or hepatobiliary-pancreatic cancer; and 3) signed informed consent.

One well-trained research nurse explained the purpose of the survey and received written informed consent from all participants before they were enrolled in the study. All participants completed the questionnaire by themselves. With the agreement of the participants, clinical information of each patient was collected from medical records. This study was approved by the Institutional Review Board of the Association for the Accreditation of Human Research Protection Program, approved by Samsung Medical Center. The study was carried out in accordance with the tenets of the Declaration of Helsinki.

\section{Questionnaire}

The questionnaire consisted of 21 questions based on an Index of Clinical Trial Understanding [17], and included questions that used a Visual analogue scale (VAS) score, as well as single- and multiple-choice questions. The survey was developed in collaboration with the Biostatistics Core at Samsung Medical Center. A VAS between 0 and 10 was used in the survey to evaluate the level of awareness of clinical trials and participation in them. A VAS score of zero indicated 'never' and 10 indicated 'absolute'. Eight of the questions concerned demographics such as age, sex, travel distance from the hospital, level of education, residence, marital status, economic status, and religion. Eight more questions asked about cancer clinical trial understanding (awareness) based on an Index of Clinical Trial Understanding [17], and the remaining five questions were about willingness to participate in clinical trials (Additional file 1).

\section{Statistical analyses}

The Kruskal-Wallis rank sum test and the Mann-Whitney test were used in the analysis of awareness and willingness according to patient characteristics. Fisher's Exact Test for Count Data was used, depending on the presence or absence of clinical trial experience. The VAS score with multiple factors (answers for single-choice or multiplechoice questions) was analyzed by Kruskal-Wallis rank sum test or Kruskal-Wallis chi-squared test. VAS scores of both groups were analyzed by Spearman correlation analysis. A biostatistician was consulted for all statistical designs and analyses and all tests were considered statistically significant at a $p<0.05$.

\section{Results}

\section{Patient cohort}

From July $1^{\text {st }}$ to November $30^{\text {th }}$ of 2011 , a total of 1,000 patients were asked to participate in the study, and 675 patients $(67.5 \%)$ agreed to complete the questionnaire. Patients who were diagnosed with gastrointestinal or hepatobiliary-pancreatic cancer (gastric, colorectal, esophageal, small intestinal, hepatobiliary, pancreatic cancer) at Samsung Medical Center in Korea were enrolled in the study. Table 1 shows the participant characteristics at baseline. The age of the participants ranged widely from 31 to 86 years, with a median age of 60 years. More patients were male than female $(n=438,64.9 \%$ vs. $n=237$, $35.1 \%$ ). High school was the most frequent level of education (47.0\%) and most participants were married (90.8\%). Colorectal cancer was the most common cancer type $(\mathrm{n}=341)$ followed by gastric cancer $(\mathrm{n}=191)$, hepatobiliary cancer $(n=57)$, pancreatic cancer $(n=51)$, esophageal cancer $(n=25)$, and small bowel cancer $(n=10)$. In terms of the disease status, 254 patients $(37.7 \%)$ were in first-line palliative chemotherapy, 250 (37.0\%) were in neoadjuvant or adjuvant chemotherapy and the remaining patients $(\mathrm{N}=168,24.9 \%)$ were in more than second-line chemotherapy. A total of 127 participants $(18.8 \%)$ had a prior 
Table 1 Participant characteristics at baseline

\begin{tabular}{|c|c|c|c|}
\hline \multicolumn{2}{|l|}{ Variables } & \multirow{2}{*}{$\begin{array}{l}\begin{array}{l}\text { Frequency } \\
(\mathrm{N}=675)\end{array} \\
60 \pm 10\end{array}$} & \multirow[t]{2}{*}{$\%$} \\
\hline Age & Median(years) & & \\
\hline \multirow[t]{2}{*}{ Sex } & Male & 438 & 64.9 \\
\hline & Female & 237 & 35.1 \\
\hline \multirow{2}{*}{$\begin{array}{l}\text { Travel time (to Hospital } \\
\text { from home) }\end{array}$} & $<2$ hours & 363 & 53.8 \\
\hline & $\geq 2$ hours & 312 & 46.2 \\
\hline \multirow[t]{6}{*}{ Place of residence } & Seoul/Gyeonggido & 325 & 48.1 \\
\hline & Chungcheongdo & 125 & 18.5 \\
\hline & Gyeongsangdo & 146 & 21.6 \\
\hline & Jeollado & 48 & 7.1 \\
\hline & Gangwondo & 21 & 3.1 \\
\hline & Jejudo & 10 & 1.5 \\
\hline \multirow[t]{3}{*}{ Education level } & $\leq$ Middle school & 154 & 22.8 \\
\hline & High school graduate & 317 & 47.0 \\
\hline & $\geq$ College graduate & 204 & 30.2 \\
\hline \multirow[t]{3}{*}{ Marital status } & Married & 613 & 90.8 \\
\hline & Single & 17 & 2.5 \\
\hline & Widowed/Divorced & 45 & 6.7 \\
\hline \multirow{3}{*}{$\begin{array}{l}\text { Economic status } \\
\text { (Income/month) }\end{array}$} & $\geq 5.000 .000$ won* & 89 & 13.2 \\
\hline & $2.000 .000 \sim 5.000 .000$ won & 308 & 45.6 \\
\hline & $\leq 2.000 .000$ won & 278 & 41.2 \\
\hline \multirow[t]{5}{*}{ Religion } & Christian & 175 & 25.9 \\
\hline & Catholic & 69 & 10.2 \\
\hline & Buddhist & 196 & 29.0 \\
\hline & No religion & 231 & 34.2 \\
\hline & Other & 4 & 0.6 \\
\hline \multirow[t]{6}{*}{ Cancer type } & Gastric & 191 & 28.3 \\
\hline & Colorectal & 341 & 50.5 \\
\hline & Esophagus & 25 & 3.7 \\
\hline & Small intestinal & 10 & 1.5 \\
\hline & Hepatobiliary & 57 & 8.4 \\
\hline & Pancreatic & 51 & 7.6 \\
\hline \multirow[t]{3}{*}{ Disease status } & Neoadjuvant or adjuvant & 250 & 37.0 \\
\hline & Palliative $\leq$ first-line & 257 & 38.1 \\
\hline & Palliative $\geq$ second-line & 168 & 24.9 \\
\hline \multirow{2}{*}{$\begin{array}{l}\text { Prior history of clinical } \\
\text { trial enrollment }\end{array}$} & Yes & 127 & 18.8 \\
\hline & No & 548 & 81.2 \\
\hline
\end{tabular}

*1000 won is equivalent to one dollar.

history of clinical trial enrollment; the remainder had no prior exposure to clinical trials.

\section{Awareness of clinical trials}

The mean score responses to the question 'On a scale of 0 to 10 , how would you rate your understanding of cancer clinical trials?' was $4.25 \pm 2.5$ and nearly half of the participants $(47.9 \%)$ selected a value of 5 . Table 2 shows the relationship between awareness of clinical trials and patient baseline characteristics. A higher educational degree $(p<0.001)$, being married $(p=0.004)$, and higher economic status $(p=0.001)$ were associated with a higher rate of awareness of clinical trials, whereas sex, travel distance from hospital, residing province in Korea, and type of religion were not significantly associated with clinical trial awareness.

\section{Cancer clinical trial understanding}

Cancer clinical trial understanding was measured using a revised Index of Clinical Trial Understanding (ICTU) [17]. When asked about their knowledge of a control group (Q\#10, Table 3), more than 50\% of patients (361 of 695) were aware that a randomized clinical trial was the most appropriate method to prove the efficacy of a new cancer drug. More than $80 \%$ of patients (545 of 675 ) agreed (VAS score $>5$ ) that a cancer clinical trial tested a new drug by randomizing patients to novel treatment vs. placebo $(\mathrm{Q} \# 14$, mean VAS $=6.1 \pm 3.1)$. Nevertheless, when

Table 2 Patient awareness of clinical trials and willingness to participate

\begin{tabular}{|c|c|c|c|c|c|}
\hline \multicolumn{2}{|l|}{ Variable } & \multicolumn{2}{|c|}{$\begin{array}{l}\text { Awareness } \\
\text { (P-value) }\end{array}$} & \multicolumn{2}{|c|}{$\begin{array}{l}\text { Participation } \\
\text { (P-value) }\end{array}$} \\
\hline \multirow[t]{2}{*}{ Sex } & Male & 4.4 & 0.082 & 5.2 & 0.011 \\
\hline & Female & 4.0 & & 4.6 & \\
\hline \multirow{2}{*}{$\begin{array}{l}\text { Distance from } \\
\text { hospital }\end{array}$} & $<2$ hour & 4.3 & 0.919 & 5.0 & 0.976 \\
\hline & $\geq 2$ hour & 4.2 & & 5.0 & \\
\hline \multirow{6}{*}{$\begin{array}{l}\text { Place of } \\
\text { residence }\end{array}$} & City of Seoul/Suburb & 4.2 & 0.895 & 4.9 & 0.865 \\
\hline & Chungcheongdo & 4.4 & & 5.3 & \\
\hline & Gyeongsangdo & 4.1 & & 5.0 & \\
\hline & Jeollado & 4.3 & & 5.1 & \\
\hline & Gangwondo & 5.0 & & 5.0 & \\
\hline & Jejudo & 4.1 & & 4.2 & \\
\hline \multirow{3}{*}{$\begin{array}{l}\text { Highest level } \\
\text { of education }\end{array}$} & $\leq$ Middle school & 3.2 & $<0.001$ & 4.6 & 0.286 \\
\hline & High school & 4.3 & & 5.0 & \\
\hline & $\geq$ University & 5.0 & & 5.2 & \\
\hline \multirow[t]{3}{*}{ Marital status } & Married & 4.4 & 0.004 & 5.0 & 0.685 \\
\hline & Single & 3.2 & & 5.2 & \\
\hline & Widowed/Divorced & 3.2 & & 4.5 & \\
\hline \multirow{3}{*}{$\begin{array}{l}\text { Economic status } \\
\text { (Income/month) }\end{array}$} & $\geq 5.000 .000$ won & 5.0 & 0.001 & 5.4 & 0.310 \\
\hline & 2.000.000 5.000.000won & 4.4 & & 5.0 & \\
\hline & $\leq 2.000 .000$ won & 3.8 & & 4.8 & \\
\hline \multirow[t]{5}{*}{ Religion } & Christian & 4.2 & 0.552 & 5.4 & 0.078 \\
\hline & Catholic & 4.6 & & 4.4 & \\
\hline & Buddhist & 4.1 & & 5.2 & \\
\hline & No religion & 4.3 & & 4.7 & \\
\hline & Other & 6.5 & & 5.0 & \\
\hline
\end{tabular}


Table 3 Cancer clinical trial understanding

\begin{tabular}{|c|c|c|c|}
\hline Question items & answers & $\mathrm{N}$ & $\%$ \\
\hline \multirow{3}{*}{$\begin{array}{l}\text { Q\#10 Which method do you think would be more effective } \\
\text { in determining the effectiveness of the new drug? }\end{array}$} & 1. Give the new drug to 1000 newly diagnosed cancer patients. & 100 & 14.8 \\
\hline & $\begin{array}{l}\text { 2. Give the new drug to } 500 \text { newly diagnosed cancer patients } \\
\text { and give the currently used drug to } 500 \text { other newly diagnosed } \\
\text { patients and see which group improves the most. }\end{array}$ & 361 & 53.5 \\
\hline & 3. Not sure & 214 & 31.7 \\
\hline \multirow[t]{4}{*}{ Q\#11 Randomization } & $\begin{array}{l}\text { 1. Patients should be allowed to select the test group that they } \\
\text { want. }\end{array}$ & 214 & 31.7 \\
\hline & $\begin{array}{l}\text { 2. Patients need to be assigned to a test group randomly to } \\
\text { make the test accurate. }\end{array}$ & 167 & 24.7 \\
\hline & 3. It doesn't make any difference; either approach will work. & 106 & 15.7 \\
\hline & 4. Not sure & 188 & 27.9 \\
\hline \multirow{5}{*}{$\begin{array}{l}\text { Q\#12 If a doctor were to tell you that patients in a clinical } \\
\text { trial were to be assigned to the new therapy and the } \\
\text { standardtherapy randomly, do you understand randomly } \\
\text { to mean that patients would be assigned by:* }\end{array}$} & 1. The severity of their disease. & 235 & 33.0 \\
\hline & $\begin{array}{l}\text { 2. An independent factor such as the two last digits of a } \\
\text { patient's telephone number.* }\end{array}$ & 38 & 5.3 \\
\hline & 3. The kind of health insurance that they have. & 14 & 2.0 \\
\hline & $\begin{array}{l}\text { 4. The doctor depending on which group needs more } \\
\text { participants. }\end{array}$ & 311 & 43.7 \\
\hline & 5. I am not sure what "randomly" means. & 114 & 16.0 \\
\hline \multirow{5}{*}{$\begin{array}{l}\text { Q\#13 If a doctor were to tell you that patients in a clinical } \\
\text { trial were to be assigned to the new therapy and the } \\
\text { standard therapy randomly, do you understand standard } \\
\text { therapy to mean:* }\end{array}$} & 1. An average cancer therapy, not the best and not the worst. & 106 & 15.0 \\
\hline & 2. The best available therapy for that particular cancer. & 317 & 44.9 \\
\hline & 3. A placebo or sugar pill with no medical value. & 5 & 0.7 \\
\hline & 4. An experimental therapy involving a new drug for cancer. & 79 & 11.2 \\
\hline & 5. I am not sure what "standard therapy" means. & 199 & 28.2 \\
\hline
\end{tabular}

questioned about their knowledge of random assignment, 214 of 695 patients $(31.7 \%)$ answered that a treatment group can be selected based on the patient's preference in a randomized trial. Each respondent was subsequently asked about the meaning of random assignment. Approximately $80 \%$ of the patients answered that they will be randomly assigned according to the severity of their disease or by a physician's decision. When asked about their knowledge of standard therapy, $45 \%$ of patients (317 of 675) understood the meaning of standard treatment to be the best available therapy for that particular cancer and $15 \%$ (106 of 675) regarded standard treatment as an average cancer therapy. Knowledge of placebo was tested using a VAS score ( 0 , completely disagree to 10 , completely agree). Item Q\#14 on the questionnaire asked how much participants agreed with the following statement: "When new cancer drugs are tested, half of the subjects always receive a placebo instead of the new medicine." Item Q\#15 provided a measure of the general understanding of the purpose of a clinical trial and asked how much participants agreed with the following statement: "Clinical trials are essential to advancing medical science and improving the standard of care." In general, cancer patients were well aware of the necessity and purpose of cancer clinical trials with a mean VAS score of $8.1 \pm 2.5$. The most frequent source for obtaining information about clinical trials was a physician $(n=391,52 \%)$ followed by mass media ( $n=273,36.6 \%)$, other patients $(n=52,6.9 \%)$, and the internet $(n=25,3.3 \%)$.

\section{Participation in clinical trials}

The VAS score evaluation of the willingness to participate in clinical trials produced a mean score of $5.0 \pm 3.1$. The total score had an even distribution from 0 to 10 and 256 patients (37.9\%) selected 5 as the VAS score. Table 2 shows the relationship between willingness to participate in clinical trials and patient characteristics at baseline. Men were more likely to participate in clinical trials than women $(p=0.001)$. Importantly, there was a discrepancy between awareness and participation in clinical trials. Patients with a higher level of education that were married and had a higher income had a better understanding of clinical trials. However, the understanding of clinical trials did not directly translate into willingness to participate. Willingness was not affected by level of education $(p=0.286)$ or economic status $(p=0.310)$. Of note, patients who obtained their information from physicians were more likely to participate in clinical trials $(p<0.001)$, whereas patients who acquired information from mass media were less likely to participate (Table 4, $p=0.027$ ). The most influential person involved in the decision to participate in clinical trials 
Table 4 Willingness to participate in a clinical trial

\begin{tabular}{|c|c|c|c|c|}
\hline Question & Answers & $N(\%)$ & Participation in a clinical trial & p-value \\
\hline \multirow[t]{5}{*}{ Source of information about clinical trials* } & Physician & $391(52.0)$ & 5.4 & $<0.001$ \\
\hline & Mass media & 273(36.6) & 4.7 & 0.027 \\
\hline & Other patients & $52(6.9)$ & 4.8 & 0.696 \\
\hline & Internet & 25(3.3) & 5.3 & 0.642 \\
\hline & Other & $11(1.5)$ & 3.7 & 0.195 \\
\hline \multirow[t]{2}{*}{ Prior participation to clinical trials } & Yes & $127(18.8)$ & 6.8 & $<0.001$ \\
\hline & No & $548(81.2)$ & 4.6 & \\
\hline \multirow[t]{6}{*}{ The decision-making person for clinical trial enrollment* } & Self & $473(62.4)$ & 5.1 & 0.298 \\
\hline & Husband, wife & $61(8.0)$ & 5.5 & 0.187 \\
\hline & Children & $28(3.7)$ & 4.1 & 0.150 \\
\hline & Parents & $1(0.1)$ & 5.0 & 0.968 \\
\hline & Family council & 183(24.1) & 4.8 & 0.345 \\
\hline & Other & $12(1.6)$ & 6.0 & 0.269 \\
\hline \multirow[t]{6}{*}{ Most influential factor for clinical trial participation } & Exposure to a new drug & 142(21.0) & 6.1 & $<0.001$ \\
\hline & Financial benefit & $50(7.4)$ & 5.3 & \\
\hline & Contribution to medicine & 119(17.6) & 5.7 & \\
\hline & Physician's recommendation & $181(26.8)$ & 4.4 & \\
\hline & No other treatment option & 178(26.4) & 4.1 & \\
\hline & Other reasons & $5(0.7)$ & 7.6 & \\
\hline \multirow[t]{5}{*}{ Most influential factor for refusal to participate } & Negative perception of clinical trials & 193(28.6) & 4.5 & 0.035 \\
\hline & Unconfirmed treatment & $320(47.4)$ & 5.2 & \\
\hline & Frequent hospital visits & $53(7.9)$ & 5.8 & \\
\hline & Prefers standard treatment & $101(15.1)$ & 4.9 & \\
\hline & Other reasons & $8(1.2)$ & 5.8 & \\
\hline
\end{tabular}

was "patient him- or her-self" ( $n=473,62.4 \%)$, followed by "family" ( $\mathrm{n}=183,24.1 \%)$. A common reason for cancer trial participation was physician recommendation $(\mathrm{n}=181,26.8 \%)$ and no other treatment options $(\mathrm{n}=178$, 26.4\%). Nevertheless, the patients who selected these two answers showed a lower level of willingness to participate. Conversely, patients who provided exposure to a new drug as the most influential factor for participation demonstrated the highest likelihood of clinical trial participation (6.141, $p<0.001)$. The most important reason for refusal to participate was unconfirmed treatment $(n=320,47.4 \%)$ followed by negative perception of clinical trials per se $(p=0.035)$. Patients with a negative perception of clinical trials showed the lowest willingness to participate.

\section{Comparison of patients with and without experience of clinical trials}

Among the 675 patients, 127 (18.8\%) had prior experience of cancer clinical trial participation (Table 5). Patients with previous experience in clinical trials were more willing to participate in clinical trials compared to patients without previous experience in clinical trials $(p<0.001)$.
For the question "What is the most important reason for participating if you decide to join a clinical trial?", "using a new drug" (n=39, 30.7\%) ranked first for patients with experience of clinical trials, whereas "for nothing other than treatment" $(n=159,29.0 \%)$ was the leading cause in patients without experience of clinical trials. For the question "What is most important reason for not participating if you decide not to join a clinical trial?", "the anxiety of unverified treatment" (51.2\%, $46.5 \%$, respectively) was the most common answer in both groups. The second most common answer was "objection to clinical trials themselves" (22.0\% vs. $30.1 \%)$ and the difference between the two groups was statistically significant $(p=0.019)$.

\section{Discussion}

Korea has been facing a rapid increase in cancer incidence [18], and the volume of cancer clinical trials has increased accordingly. Progress in cancer treatment can only come from investigations of novel therapies and treatment strategies performed in the setting of well conducted clinical trials [1]. Because participation in 
Table 5 Prior exposure to clinical trials and willingness to participate

\begin{tabular}{|c|c|c|c|c|}
\hline Question & Answers & $\begin{array}{l}\text { Patients in previous } \\
\text { clinical trials } \\
(\mathrm{N}=127)(\%)\end{array}$ & $\begin{array}{l}\text { Patients never in } \\
\text { clinical trial } \\
(\mathrm{N}=548)(\%)\end{array}$ & p-value \\
\hline \multirow[t]{6}{*}{ Most influential factor for clinical trial participation } & Using a new drug & $39(30.7)$ & $103(18.8)$ & \multirow[t]{6}{*}{0.001} \\
\hline & Economic benefit & $8(6.3)$ & $42(7.7)$ & \\
\hline & Contribute to medical development & $21(16.5)$ & 98(17.9) & \\
\hline & Physician's recommendation & $37(29.1)$ & $144(26.3)$ & \\
\hline & No other treatment option & 19(15.0) & 159(29.0) & \\
\hline & Other & $3(2.4)$ & $2(0.4)$ & \\
\hline \multirow[t]{5}{*}{ Most influential factor for refusal to participate } & Negative perception of clinical trials & $28(22.0)$ & 165(30.1) & \multirow[t]{5}{*}{0.019} \\
\hline & Unconfirmed treatment & $65(51.2)$ & 255(46.5) & \\
\hline & Frequent hospital visits & $8(6.3)$ & $45(8.2)$ & \\
\hline & Prefers standard treatment & $21(16.5)$ & $80(14.6)$ & \\
\hline & Other reasons & $5(4.9)$ & $3(0.6)$ & \\
\hline
\end{tabular}

clinical trials has frequently been associated with a higher survival rate [19], clinical trials have become an important facet of oncology, and the need for clinical studies continues to grow. Our study has shown that willingness to participate in clinical trials is intermediate in Asian patients with GI and hepatobiliary-pancreatic cancer. The mean VAS score of 5.0, the median score of 5 , and evenly distributed total score from 0 to 10 showed some differences from results of prior studies performed in Western countries, where the majority of patients with cancer were willing to consider participating in clinical trials [14,17,20,21].

Overall, Korean cancer patients understood the need for two treatment arms to prove drug efficacy $(\mathrm{N}=361$, $53.5 \%$ ), which is considerably higher than in the Western studies (33\% of the public and $37 \%$ of cancer survivors) [17]. Nevertheless, our study indicated that more than $70 \%$ of patients did not possess accurate knowledge of randomized trials: $31.7 \%(n=214)$ of patients thought they could choose the study treatment arm in a randomized trial and 43.7\% ( $\mathrm{n}=311)$ answered that a doctor's decision is the most influential factor for randomization. Only 5.3\% of patients understood the exact meaning of randomization, which is substantially lower than the percentage reported in Western studies (63\% of the public and $67 \%$ of cancer survivors). Furthermore, less than half of our cancer patients were aware that standard treatment referred to the best current practice for a specific disease while $66 \%$ of the Western cancer patients were aware of the meaning of standard treatment in cancer care [17]. Taken together, although a higher rate of cancer patients were aware of randomized trials than in the West, a much smaller percentage of cancer patients had precise knowledge of the randomization process or of assignment of a treatment arm in randomized trials. Based on our results, more detailed explanations on the randomization procedure should be provided to patients at our hospital, since there was a high discordance rate between the awareness and the understanding of a randomized clinical trial.

Interestingly, a higher level of awareness did not always result in increased willingness to participate in clinical trials, in contrast to the findings of previous Western studies $[4,7,21-24]$. This might represent one of the peculiar features of Asian cancer patients that should be confirmed in another cancer patient cohort.

As shown in Tables 4 and 5, the most influential factor for willingness to participate in clinical trials was 'physician's recommendation' (26.8\%) and this was similar to Western findings which showed the strongest predictor of expected enrollment of clinical trials was encouragement by the physician [17]. In contrast to a common belief, however, the main decision-making person for clinical trial participation in Korea was the patient (473 of $675,62.4 \%)$.

In this study cohort, a total of 127 participants (18.8\%) had a prior history of clinical trial enrollment. This population represented a unique patient population with different behavior from the remaining patients. For instance, there was high concordance between clinical trial awareness and willingness to participate $(p<0.001)$. In addition, the most common motivation for clinical trial participation was exposure to a new drug (30.7\% vs. 18.8\%; prior experience vs. no experience group, Table 5). In addition, the negative perception of clinical trials was significantly lower in patients $(n=28$ of $127,22 \%)$ with prior experience when compared with no experience $(n=165$ of $548,30.1 \%)$.

We note that our study has some limitations. First, an inherent selection bias may exist owing to the fact that the study was conducted in only one tertiary academic hospital. Second, another selection bias was introduced 
because our data did not include all 1000 patients who were asked to join this survey and only $67.5 \%$ of patients completed the questionnaire. In addition, the percentage of clinical trial participants may have influenced and altered the results of this survey. The rate of clinical trial participants for GI and hepatobiliary-pancreatic cancer at Samsung Medical Center ranges from $10-20 \%$ at all times which is in accordance with the proportion of clinical trial participants in this study (18.8\%). Hence, the proportion of participants was not biased or misrepresented in this study.

\section{Conclusions}

In conclusion, our study involved a large patient cohort and we used VAS scores to inquire about the awareness of, and willingness to participate in, clinical trials in Asian cancer patients. Based on this study, we plan to do a follow-up study in five or ten years to analyze the evolving trend in perception of clinical trials in Korean cancer patients. Through this survey study, we established and defined unique features of our patients. Understanding a cancer patient's perception, willingness to participate, and influential factors underlying decisions could facilitate patient recruitment for clinical trials in Asia.

\section{Additional file}

\section{Additional file 1: Questionnaire.}

\section{Competing interests}

The authors declare that they have no competing interests.

\section{Authors' contributions}

$J L, S H P, J O P, H Y L, W K K$ and Y SP contributed substantially to the conception and design of this study. MKC, JYH, SP, CHM, WC and YSK contributed to data acquisition. SK analyzed data. SJL and LCP interpreted data and prepared a draft manuscript. JL and YSP produced a final draft and provided approval for submission of this manuscript. All authors read and approved the final manuscript.

\section{Author details}

'Division of Hematology/Oncology, Department of Medicine, Samsung Medical Center, Sungkyunkwan University School of Medicine, 50 Irwondong Gangnam-gu, Seoul 135-710, Korea. ${ }^{2}$ Department of Internal Medicine, Kosin University Gospel Hospital, Busan, Korea. ${ }^{3}$ Biostatistics team, Samsung Biomedical Research Institute, Samsung Medical Center, Seoul, Korea.

Received: 29 July 2012 Accepted: 26 November 2012

Published: 12 December 2012

\section{References}

1. Virani S, Burke L, Remick SC, Abraham J: Barriers to recruitment of rural patients in cancer clinical trials. J Oncol Pract 2011, 7(3):172-177.

2. Kim JW, Kim SJ, Chung YH, Kwon JH, Lee HJ, Chung YJ, Kim YJ, Oh DY, Lee SH, Kim DW, et al: Cancer patients' awareness of clinical trials, perceptions on the benefit and willingness to participate: Korean perspectives. Br J Cancer 2008, 99(10):1593-1599.

3. Madsen SM, Holm S, Riis P: Attitudes towards clinical research among cancer trial participants and non-participants: an interview study using a Grounded Theory approach. J Med Ethics 2007, 33(4):234-240.
4. Comis RL, Miller JD, Aldige CR, Krebs L, Stoval E: Public attitudes toward participation in cancer clinical trials. J Clin Oncol 2003, 21(5):830-835.

5. Madsen S, Holm S, Riis P: Ethical aspects of clinical trials: the attitudes of the public and out-patients. J Intern Med 1999, 245(6):571-579.

6. Madsen SM, Mirza MR, Holm S, Hilsted KL, Kampmann K, Riis P: Attitudes towards clinical research amongst participants and nonparticipants. J Intern Med 2002, 251(2):156-168

7. Ellis PM: Attitudes towards and participation in randomised clinical trials in oncology: a review of the literature. Ann Oncol 2000, 11(8):939-945.

8. McDonald AM, Knight RC, Campbell MK, Entwistle VA, Grant AM, Cook JA, Elbourne DR, Francis D, Garcia J, Roberts I, et al: What influences recruitment to randomised controlled trials? A review of trials funded by two UK funding agencies. Trials 2006, 7:9.

9. White C, Gilshenan K, Hardy J: A survey of the views of palliative care healthcare professionals towards referring cancer patients to participate in randomized controlled trials in palliative care. Support Care Cancer 2008, 16(12):1397-1405.

10. White CD, Hardy JR, Gilshenan KS, Charles MA, Pinkerton CR: Randomised controlled trials of palliative care - a survey of the views of advanced cancer patients and their relatives. Eur J Cancer 2008, 44(13):1820-1828.

11. Bergenmar M, Molin C, Wilking N, Brandberg Y: Knowledge and understanding among cancer patients consenting to participate in clinical trials. Eur J Cancer 2008, 44(17):2627-2633.

12. Markman M, Petersen J, Montgomery R: Influence of tumor type, disease status, and patient age on self-reported interest regarding participation in cancer clinical trials. Cancer 2006, 107(4):849-853.

13. Wright JR, Whelan TJ, Schiff S, Dubois S, Crooks D, Haines PT, DeRosa D, Roberts RS, Gafni A, Pritchard K, et al: Why cancer patients enter randomized clinical trials: exploring the factors that influence their decision. J Clin Oncol 2004, 22(21):4312-4318.

14. Jenkins V, Farewell D, Batt L, Maughan T, Branston L, Langridge C, Parlour L, Farewell V, Fallowfield $L$ : The attitudes of 1066 patients with cancer towards participation in randomised clinical trials. $\mathrm{Br} J$ Cancer 2010, 103(12):1801-1807.

15. Map of All Studies in ClinicalTrials.gov. ClinicalTrials.gov.

16. Go RS, Frisby KA, Lee JA, Mathiason MA, Meyer CM, Ostern JL, Walther SM, Schroeder JE, Meyer LA, Umberger KE: Clinical trial accrual among new cancer patients at a community-based cancer center. Cancer 2006, 106(2):426-433.

17. Miller JD, Kotowski MR, Comis RL, Smith SW, Silk KJ, Colaizzi DD, Kimmel LG: Measuring cancer clinical trial understanding. Health Commun 2011, 26(1):82-93.

18. Jung KW, Park S, Kong HJ, Won YJ, Boo YK, Shin HR, Park EC, Lee JS: Cancer statistics in Korea: incidence, mortality and survival in 2006-2007. $J$ Korean Med Sci 2010, 25(8):1113-1121.

19. Stiller CA: Centralised treatment, entry to trials and survival. $\mathrm{Br} J$ Cancer 1994, 70(2):352-362.

20. Fallowfield LJ, Jenkins V, Brennan C, Sawtell M, Moynihan C, Souhami RL: Attitudes of patients to randomised clinical trials of cancer therapy. Eur J Cancer 1998, 34(10):1554-1559.

21. Wallington SF, Luta G, Noone AM, Caicedo L, Lopez-Class M, Sheppard V, Spencer C, Mandelblatt J: Assessing the Awareness of and Willingness to Participate in Cancer Clinical Trials Among Immigrant Latinos. J Community Health 2012, 37(2):335-343.

22. Ross S, Grant A, Counsell C, Gillespie W, Russell I, Prescott R: Barriers to participation in randomised controlled trials: a systematic review. J Clin Epidemiol 1999, 52(12):1143-1156.

23. Lara PN Jr, Paterniti DA, Chiechi C, Turrell C, Morain C, Horan N, Montell L, Gonzalez J, Davis S, Umutyan A, et al: Evaluation of factors affecting awareness of and willingness to participate in cancer clinical trials. J Clin Oncol 2005, 23(36):9282-9289.

24. Shavers VL, Lynch CF, Burmeister LF: Racial differences in factors that influence the willingness to participate in medical research studies. Ann Epidemiol 2002, 12(4):248-256.

doi:10.1186/1471-2407-12-594

Cite this article as: Lee et al:: Unique perception of clinical trials by Korean cancer patients. BMC Cancer 2012 12:594. 